\title{
Unusual Dilaceration of Maxillary Central Incisor: A Case Report
}

\author{
Amulya Vanapatla, P. Rajani, Tulasi Priya \\ Department of Conservative Dentistry and Endodontics, Kamineni Institute of Dental Sciences, Narketpally, Telangana, India
}

Email for correspondence: doctor.amulya.mds@gmail.com

\begin{abstract}
Dilaceration of teeth can occur as a result of trauma to its primary predecessors. Crown dilacerations are rare rather than root dilacerations. A variety of factors, including crown and root dilacerations, might complicate endodontic treatment. Hence, when attempting to perform endodontic procedures, the clinician must use great care to avoid mishaps in teeth with significant dilacerations. The present case report describes endodontic management of dilacerated maxillary central incisor.
\end{abstract}

Key words: Dilaceration, endodontic management, maxillary central incisor

\section{INTRODUCTION}

Key to successful endodontic treatment is a thorough knowledge, respect, and appreciation for root canal anatomy together with careful, thoughtful, and meticulously performed cleaning and shaping procedures. A variety of factors, including crown and root dilacerations, might complicate this treatment, so when attempting to perform endodontic procedures, the clinician must use great care to avoid mishaps in teeth with significant dilacerations. ${ }^{[1-3]}$

Dilaceration is defined as an angulation or sharp bend or curve in the linear relationship of the crown of a tooth to its root. The term was first coined by Tomes in 1848. It usually occurs subsequent to intrusion, avulsion, and subluxation injuries of primary teeth and is seen to commonly affect permanent maxillary central incisors. ${ }^{[4-6]}$

The criteria for recognizing root dilaceration vary in the literature. According to some authors, a tooth is considered to have a dilaceration toward the

\section{Quick Response Code Article Info:}

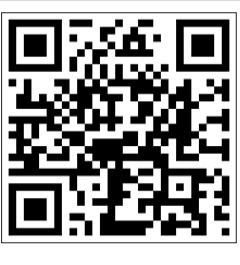

doi: $10.5866 / 2017.9 .10183$

Received: 29-07-2017

Revised: 30-08-2017

Accepted: 15-09-2017

Available Online: 27-11-2017 (www.nacd.

in)(C NAD, 2017 - All rights reserved mesial or distal direction if there is a 90 angle or greater along the axis of the tooth or root, whereas others defined dilaceration as a deviation from the normal axis of the tooth of 20 or more in the apical part of the root. ${ }^{[7-9]}$

The most widely accepted cause is mechanical trauma to the primary predecessor tooth, which results in dilaceration of the developing succedaneous permanent tooth. The calcified portion of the permanent tooth germ is displaced in such a way that the remainder of the permanent tooth germ forms at an angle to it. ${ }^{[10]}$

The recognition and diagnosis of a dilaceration are essential for any tooth that requires root canal treatment. Radiographic examination is required to diagnose a dilaceration of a tooth root. ${ }^{[9]}$ Additional radiographs from different angles are recommended to assist with the diagnosis. The present case report presents the endodontic management of dilacerated maxillary central incisor.

\section{CASE REPORT}

A 20-year-old female patient reported to the department of conservative dentistry and endodontics with the complaint of pain and discoloration in the maxillary anterior region. The patient's medical history was non-contributory. Dental history revealed trauma to the anterior maxilla at 2-3 years of age due to fall from stairs, following which she had lost his left primary incisors. No dental treatment was undertaken for the same 
until the patient visited the dental clinic with the complaint of pain in relation to the left upper front tooth. Her parents confirmed that the permanent successors had erupted with alterations in color and shape, and although they were dissatisfied with the esthetics, they had never visited a dentist earlier.

On clinical examination, maxillary left central incisor was affected tooth with yellowish brown discoloration, and on closer examination, it appeared that the coronal part of the crown was bent palatally and distally [Figure 1]. Vitality testing with thermal and electrical pulp tests showed no response. Tenderness on percussion and pain on palpation were noted in relation to the same tooth.

Intraoral radiographic examination revealed that the root of maxillary left central incisor was bent distally at an angulation more than 45 to the crown portion, and well-defined periapical radiolucency was seen at the root apex [Figure 2]. Based on these clinical and radiographic findings, a diagnosis of dilaceration of left central incisor having symptomatic apical periodontitis was made. Moreover, treatment plan was non-surgical root canal treatment followed by esthetic correction of affected tooth.

Access opening was done under local anesthesia, and orifice was located carefully. Orifice was located when it was approached more lingually and distally without any perforation. Initial apical file with no \#15 k file was placed into the canal, and radiograph was taken. Working length was 19 $\mathrm{mm}$ from the coronal reference point [Figure 3]. Biomechanical preparation was done using protaper rotary file system till F3 file along with irrigation with $3 \%$ sodium hypochlorite $17 \%$ ethelene diamine tetraacetic acitic acid and $0.9 \%$ normal saline in between filing. Master cone was placed in the canal, and a confirmative radiograph was taken. Calcium hydroxide dressing was given, and the patient was recalled after 5 days for obturation. In the next visit, temporary restoration was removed, and canal was irrigated with $3 \%$ sodium hypochlorite and $0.9 \%$ normal saline. Then, canal was dried with paper points, and obturation was done using 6\% GP point and lateral condensation technique [Figure 4]. Entrance filing was done with glass ionomer cement. Metal ceramic crown was placed [Figure 5].

\section{DISCUSSION}

Awareness and understanding of the presence of unusual external and internal root canal

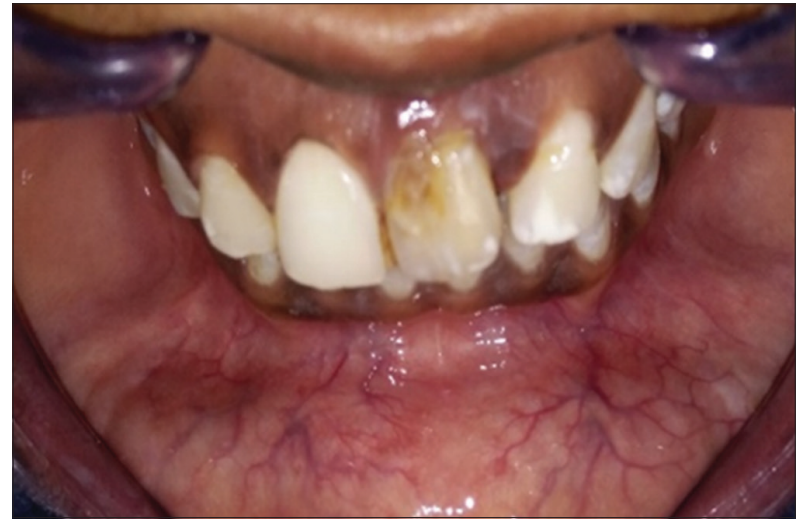

Figure 1: Pre-operative photograph showing discolored maxillary left central incisor

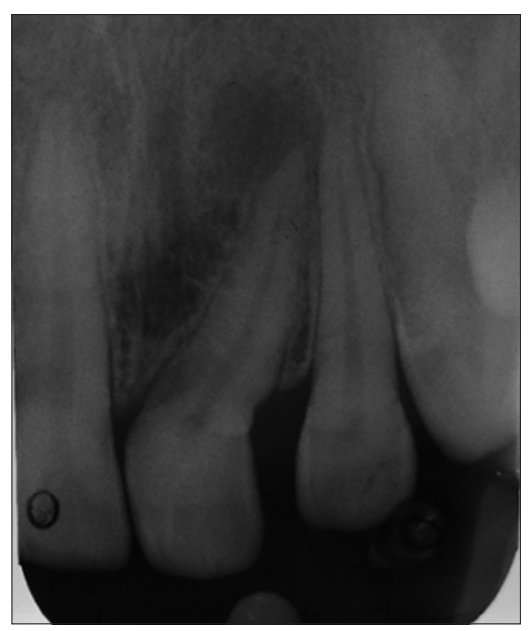

Figure 2: Intraoral radiographic examination showing dilacerations along with well-defined periapical radiolucency at the root apex

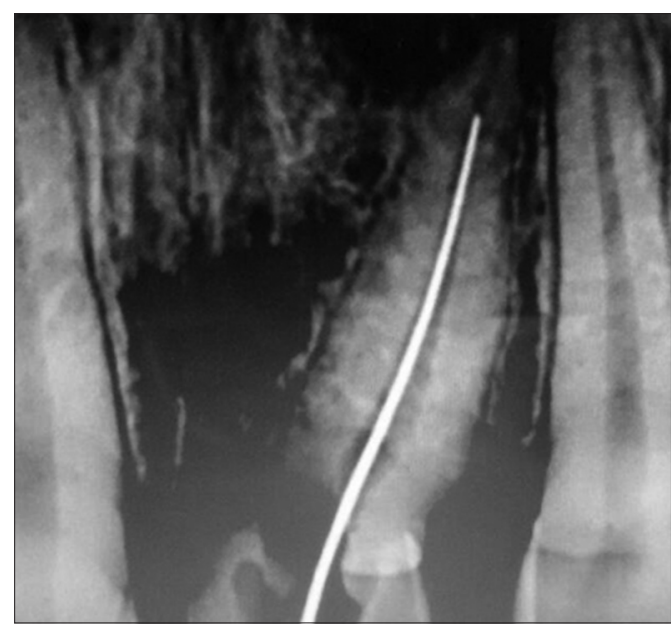

Figure 3: Working length radiograph 


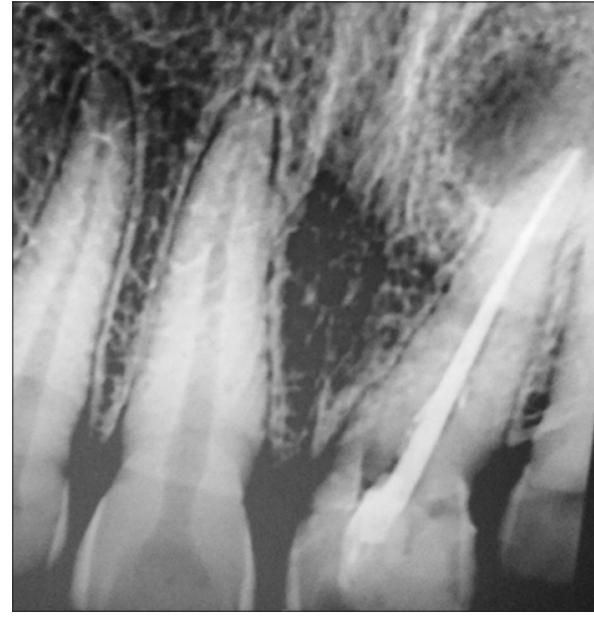

Figure 4: Post-obturation radiograph

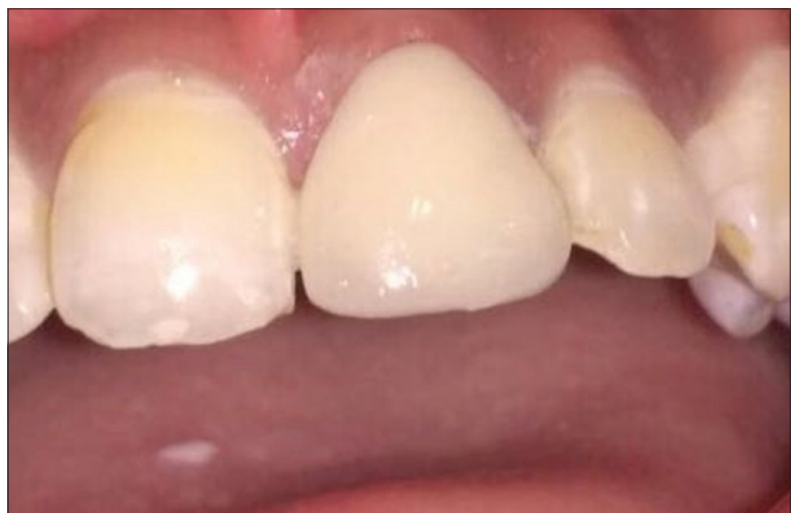

Figure 5: Post-operative photograph showing the placement of metal ceramic crown in maxillary left central incisor

morphology contribute to the successful outcome of the root canal treatment. ${ }^{[11]}$

In dilacerated teeth, the accepted basic endodontic techniques must be strictly followed, that is, good preoperative and working radiographs, unobstructed access to the root canal orifice, as direct access as possible to the apical-third of the canal, thorough irrigation and hermetic seal.

Diagnosing root dilacerations before commencing endodontic treatment is essential to allow proper and safe use of endodontic instruments within the curved roots. ${ }^{[7,9,12]}$ Failure to recognize the multiplanar nature of the dilaceration is one of the factors that might contribute to the higher rate of unfavorable outcomes. To overcome this problem, periapical radiographs that determine the direction of dilaceration are adequate. ${ }^{[9]}$ However, such diagnostic findings can be confirmed by a computed tomography scan, which can help to determine the exact position and angulation of the dilacerations. ${ }^{[13]}$

Direct access to the apical foramen, as much as possible, is an important benefit gained through the access cavity preparation. To provide the most direct access possible to the apical foramen, enough tooth structure must be removed to allow the endodontic instruments to be moved freely within the coronal cavity. ${ }^{[10]}$

In dilacerated teeth, it is often difficult to explore and negotiate the root canals, when an endodontic file is introduced into the root canal during treatment, it might be blocked by such irregularities, even if the file has been precurved, and this might prevent the operator from reaching the ideal working length. ${ }^{[14]}$

Hence, the use of a "scout file" can provide critical information regarding the extent and direction of a root canal dilaceration. Scout files are not just measuring wires; rather, they provide critical information before initiating shaping procedures. [1] Another problem in endodontic treatment of these cases is the inability to continuously follow the root canal curvature, and this might result in blocking of the canal, ledging, apical cavitation such as transportation and/or zipping, perforation, and instrument breakage. ${ }^{[1,12]}$ When using manual instrumentation techniques, the flexibility of the instruments with respect to their size must be considered. The outcome of root canal treatment will depend largely on complete biomechanical debridement of the canals and the elimination of microorganisms from the root canal system. ${ }^{[15]}$ The use of copious irrigation, file recapitulation, and further irrigation should be repeated more frequently in these severely curved canals. ${ }^{[1]}$

A multivisit approach should also be followed, with the use of inter appointment intracanal medicaments to increase the predictability of the treatment. Although lateral compaction of curved canals can be very effective in most teeth, this technique might be difficult and sometimes impossible in dilacerated canals. If small, flexible spreaders cannot reach to within $1 \mathrm{~mm}$ of the working length or the taper of the root canal preparation is less than that of the spreader, then, lateral compaction is not the technique of choice. ${ }^{16}$ If the lateral compaction technique is chosen, then spreaders made from NiTi are highly recommended for the filling of severely curved root canal systems 
because they will penetrate to greater depths and distribute forces more evenly than stainless steel spreaders. ${ }^{[1]}$

The use of warm or thermoplasticized guttapercha techniques might be more applicable in many cases, although these techniques might also be difficult to perform because of the presence of the dilacerations. ${ }^{[16]}$

The prognosis of dilacerated teeth that require endodontic treatment varies according to the severity of the deformity and the practitioner's skills..$^{[3,16]}$ It will also depend on many other factors such as the reason why endodontic treatment was required, how much tooth structure remains, and the prognosis for any restoration that is placed on the tooth.

\section{CONCLUSION}

Dilacerated teeth are not common, but they do pose a number of diagnostic, management, and prognostic challenges to dental practitioners. The presence of a dilaceration must be identified before treatment, and this can be achieved by a thorough clinical and radiographic examination.

\section{REFERENCES}

1. Cohen S, Burns RC. Pathways of the Pulp. $8^{\text {th }}$ ed., Vol. 94. St Louis: Mosby; 2002. p. 243-74, 325-31, 644-5.

2. Gupta S. Endodontic miscellany: Conventional endodontics for complex root-canal morphology. Endodontology $2002 ; 14: 28-9$

3. Neville BW, Damm DD, Allen CM, Bouquot JE. Oral and Maxillofacial Pathology. $2^{\text {nd }}$ ed. Philadelphia, PA: WB Saunders; 2002. p. 86-8.

4. Sharma S, Grover S, Sharma V, Srivastava D, Mittal M. Endodontic and esthetic management of a dilacerated maxillary central incisor having two root canals using cone beam computed tomography as a diagnostic aid. Case Rep Dent 2014;2014:1-7.

5. Shafer WG, Maynard KH, Bernet ML. Oral Pathology. Philadelphia, PA, USA: WB Saunders Company; 1993.

6. Tomes J. A Course of Lectures on Dental Physiology and Surgery Delivered at the Middlesex Hospital School. London, UK: John W. Parker; 1848.

7. Hamasha AA, Al-Khateeb T, Darwazeh A. Prevalence of dilaceration in Jordanian adults. Int Endod J 2002;35:910-2.

8. Malcic A, Jukic S, Brzovic V, Miletic I, Pelivan I, Anic I. Prevalence of root dilaceration in adult dental patients in Croatia. Oral Surg Oral Med Oral Pathol Oral Radiol Endod 2006;102:104-9.

9. Chohayeb AA. Dilaceration of permanent upper lateral incisors: Frequency, direction, and endodontic treatment implications. Oral Surg Oral Med Oral Pathol 1983;55:519-20.

10. Jafarzadeh H, Abbott PV. Dilaceration: Review of an endodontic challenge. J Endod 2007;33:1025-30.

11. Chakradhar Raju RV, Sathe N, Morisetty PK, Veeramachaneni C. Endodontic management of a maxillary first molar with unusual location of second mesio buccal orifice. J Conserv Dent 2010;13:162-4.

12. Walton RE, Torabinejad M. Principles and Practice of Endodontics. $2^{\text {nd }}$ ed. Philadelphia, PA: WB Saunders; 1996. p. $330-2$.

13. Agnihotri A, Marwah N, Dutta S. Dilacerated unerupted central incisor: A case report. J Indian Soc Pedod Prev Dent 2006;24:152-4

14. Lin L, Dowden WE, Langeland K. Bilateral dilaceration. J Endod 1982;8:85-7.

15. Seltzer S. Endodontology: Biologic Considerations in Endodontic Procedures. New York: McGraw-Hill; 1971. p. 386 .

16. Ingle JI, Bakland LK. Endodontics. $5^{\text {th }}$ ed. London: BC Decker Inc.; 2002. p. 409-10, 489, 540, 609-36, 776-7. 